\title{
A Study on Characteristics of the Phenomenon of National Association, Communication and Integration Embodied in the Tibetan Heroic Epic "Gesaer"
}

\author{
Jing $\mathrm{An}^{1}$ Qian Xiang ${ }^{1, *}$ \\ ${ }^{1}$ School of Law, Sichuan Minzu College, Kangding, Sichuan, China \\ *Corresponding author. Email: 603550084@qq.com
}

\begin{abstract}
"Gesaer" started its narrative from the establishment of the Tubo dynasty and continued to the separation and disintegration of the dynasty. It records the most turbulent and revolutionary historical period of the dynasty. "Gesaer" describes the process of the integration of Tibetan culture and Central Plains culture with Mongolian, $\mathrm{Tu}$ and other cultures, reflecting the process of multi-ethnic communication, exchange, and blending in China. The formation of Tibetan culture has not only the role of history, geography, culture and other factors, but also the baptism and blessing of Chinese culture. As a subculture of Chinese culture, the two belong to the same cultural ecological environment. Tibetan culture is a unique ethnic culture in Chinese culture. "Gesaer" has enriched the treasure house of Chinese culture, from which the origin and development of Chinese culture can be explored. At the same time, based on "Gesaer", the scholars can also study how the Central Plains culture represented by the three schools of Confucianism, Buddhism, and Taoism assimilated and merged the Western Regions culture, Liao and Jin cultures, Western Xia culture, Tibetan culture, and Manchurian and Mongolian culture, to form into the Chinese culture in the current days.
\end{abstract}

Keywords: "Gesaer", Cultural heritage, National association, Communication and integration.

\section{INTRODUCTION}

The epic "Gesaer" is the longest epic in the world. Since the 19th century, it has attracted the attention and focus of Western academic circles, and has been translated into English, German, Japanese, Russian, Indian, Mongolian, Latin, etc. It spreads among the Tibetan, Mongolian, Tu, Yugu, Naxi, Pumi and other ethnic groups on the QinghaiTibet Plateau in China. It tells the heroic achievement stories of King Gesaer descending from the Lower Realm to beat demons, suppress the strong and support the weak, unify the tribes, and finally go back to the heaven.[1] The nearly 100 wars of all sizes described by "Gesaer" are based on real wars that occurred during the Song and Yuan

*Project: Sichuan Province Kangba Cultural Center Key Base Project, phased results of Ganzi Tibetan Autonomous Prefecture Intangible Cultural Heritage Transformation Application Research (Project No.: KBY2020A008). dynasties. The process of war is also the process of historical formation and the process of the formation of the Chinese nation.

\section{THE EPIC "GESAER" DESCRIBES THE FORMATION OF THE CHINESE NATION IN THE SONG AND YUAN DYNASTIES}

\subsection{The Historical Value of the Epic "Gesaer"}

"Gesaer" began its narrative from the establishment of the Tubo dynasty and continued to the separation and disintegration of the dynasty. It records the most turbulent and major historical period of the dynasty. During this process, the Tibetan society, politics, economy, and culture were in an extremely unstable state, and the people's livelihood was in dire straits. This period 
was precisely the period when Han-Tibetan culture carried out economic and cultural exchanges through the Tang-Tibetan ancient road. "Gesaer" describes the process of combining Tibetan culture with Central Plains culture, and the process of combining Tibetan culture with Mongolian and $\mathrm{Tu}$ cultural traditions. From the epic, people can find the mutual reference, absorption and integration of Tibetan culture, Central Plains culture and other cultures. In the process, "Gesaer" has enriched the treasure house of Chinese culture.

\subsection{Research Status of "Gesaer"}

The study of "Gesaer" is divided into four contexts:

\subsubsection{Research That Emphasizes the Historical Value of "Gesaer"}

For the study of the historical value of "Gesaer", Sumba Yixibanjue's "Questions and Answers about Gesaer" can be the first to be recommended. For the research on the historical value of "Gesar", typical representative works that cannot be ignored include: Mr. Ren Naiqiang published an article "A Preliminary Introduction to "The Three Kingdoms of Tibet"" in "Bian Zheng Gong Lun", which comprehensively summarized her findings on "The Biography of King Gesaer" in the Xikang area. At the same time, the research results that have to mention include the article "On Ling - Gesaer's Birth Year and the Era of 'Gesaer' Epic" written by Xu Guoqiong.

\subsubsection{Research from the Aspects of National Association, National Communication, National Consciousness and National Spirit}

Typical representative works include: "A Preliminary Study of Gesaer" and "'Gesaer' and Tibetan Culture" by Jiangbian Gyatso; "Gesaer Library" edited by Wang Xingxian; Yang Enhong "Chinese Minority Hero Epic 'Gesar'"; He Feng "'Gesaer' and Tibetan Tribes"; Alai "King Gesaer" etc. Professor Jiangbian Gyatso pointed out: "Gesaer" describes the Ling kingdom, an ideal kingdom, a place full of happiness and tranquility. It is a model of the ideal world that Tibetans and other ethnic groups aspire to. The Ling kingdom described in "Gesaer" is the center of the world. The national exchanges and communication of all ethnic groups take place in Ling kingdom. In Ling kingdom, all ethnic groups show a common pursuit of truth, goodness, and beauty.

\subsubsection{From the Perspectives of Ethnology, Folklore, Linguistics and Other Multi- disciplinary Cross-cutting Perspectives and Multiple Research Methods, the Gesaer Study Becomes a Holistic, Comprehensive and Macroscopic Study}

Zhang Xiaoming's article "Thoughts on the Research of Gesaer" pointed out that being limited to the narrow perspective provided by the traditional epic theory is not conducive to the deepening of research; Huang Wenhuan: "Revisiting the Historical Connotation of Gesaer" discusses the contribution of the Tubo era to jointly building a Chinese nation and promoting the development of world civilization. In the research results, ethnologists, anthropologists, and historians have come to the conclusion: Gesaer, as a Tibetan born and raised, his behavior, moral standards, right and wrong ideas are all imprinted with the personality of the Tibetan group. Therefore, Gesaer is a typical example of Tibetan personality. From the generality of human morality, Gesaer, this ideal personality model, has super-national characteristics. This is a question that people must pay attention to when looking at Gesaer, a model of ideal personality, from the perspective of comparative national ethics. [2] For the supernational personality model, other nations will yearn for it, try to imitate and try to surpass it. Therefore, Gesaer's personality charm is a spiritual model of a multi-ethnic country and a national hero.

\subsubsection{Foreign Research}

In 1953, Ulan-Ude held an academic seminar on "Gesaer". The theme of the meeting was to start on "Gesaer"; in 1957 Dr. Cedamuding Surong (Mongolia) published "The Historical Origins of Gesaer", studied the origin of "Gesaer" and thought that the Tibetan people had close and intimate communication with other ethnic groups; in 1959 (French) R.-A. Stein published "A Study of Tibetan Epic and Rap Artists". In 1967, George N Raerieh analyzed the Tibetan text "Gesaer". 


\section{THE EPIC "GESAER" REFLECTS THE PROCESS OF CHINESE MULTI-ETHNIC ASSOCIATION, COMMUNICATION AND INTEGRATION}

The narrative epic of "Gesaer" fully embodies the important position of the core concept of "unity in diversity" in the Chinese nation community, and embodies the process of large-scale exchanges and integration between the Tibetan people and the various ethnic groups in the interior in political, economic, cultural, and artistic aspects.

\subsection{To Construct the Internal Logical Relationship Based on General Secretary Xi Jinping's Important Remarks of National Association, Communication, and Integration}

Regarding ethnic work, Xi Jinping, the general secretary of the CPC Central Committee, emphasized that as a unified multi-ethnic country, it is necessary to grasp the national unity as the lifeline of the people of all ethnic groups based on the basic national conditions, earnestly implement the Party Central Committee's plan to forge a sense of the Chinese nation's community, and establish a national outlook and a unified outlook. For the big family of the Chinese nation, all ethnic groups are brothers and sisters who unite and help each other. It is necessary to explore the origin and development of Chinese culture from the culture of each ethnic group. Cultural identity is the root and soul of national unity. [3]

\subsection{To Build a Diversified Chinese Culture, and Tibetan Culture Represented by Gesaer Belongs to One of the Dazzling Sub-cultures That Takes Han Culture as the Core}

In the turbulent history, the Han culture is gorgeous and colorful, and has become the core of the construction of Chinese culture. With Han culture as the cohesive force, the various subcultures are gradually merged to gradually form a diversified Chinese culture. Diversified subcultures include cultures from different ethnic groups, regions, and sources. After running-in, blending, and communication, they eventually converge into a multi-centripetal Chinese culture. This is the need of the big ethnic family and the essential attribute of the big ethnic family. The
Tibetan culture represented by "Gesaer" shares a common cultural heart with Chinese culture, and the cultural attributes of convergence determine that they belong to the Chinese cultural system.

As a representative of Tibetan culture, the epic "Gesaer" records the content of the social life of the Tibetan people. Through the study of "Gesaer", it is of great help for people to understand the origin of Tibetan culture, the characteristics of Tibetan culture, the origin of Chinese culture, the characteristics of Chinese culture, and the unity of Tibetan culture and Chinese culture.

\subsection{Based on the Global Influence of the Epic "Gesaer", People Can Study the Historical Data on the Mutual Acceptance, Absorption, Tolerance, and Identification of Chinese Nationalities During the Song and Yuan dynasties Recorded in the Epic, and Explore the External Influence Mechanism of National Association, Communication and Integration}

For countries in the world, the study of epic means the study of the origin of culture. It is the way human beings recognize their own childhood. For example, "Gilgamesh", everyone knows that this is the epitome of the ancient Babylonian civilization. By studying "Gilgamesh", people have learned about the civilization of the Mesopotamia. Another example is the "Homeric Epic". Through the study of "Homeric Epic", people understand Greek social life, the political economy of Greece, and even people named Greek society after Homer's era. [4]

The epic "Gesaer" is a historical testimony to the association, communication and integration of the Chinese nation. "Gesaer" vividly describes the process of the Qinghai-Tibet Plateau from falling apart to returning to the embrace of the motherland. It also shows the relationship between the QinghaiTibet Plateau and the inland of the Central Plains since the Yuan Dynasty. It praises the unity and friendship between the Tibetan and Han nationalities and other ethnic groups, and it is the historical testimony of national association, communication and integration. 


\subsection{Political Region Boundary and National Cultural Boundary}

\subsubsection{The Tibetan Dynasty in History}

The Tubo dynasty once expanded the eastern territory to the vast areas of Qing, Gan, western Sichuan and northwestern Yunnan. In many largescale wars, a large number of people flowed, including immigrants, garrisons and slaves. In the process of conquering neighboring countries by war, the output and integration of culture have become appendages and value-added parts of war and enter the historical process. Although India, Han Dynasty, Hall, Yu Wen, etc. and the Tubo Dynasty had geographical and political boundaries at that time, the ethnic cultural boundaries were different from the geographical and political boundaries at that time. In the perennial war, the integration of multiple cultures has transcended the boundaries of political regions. Especially when the Tubo Dynasty was brought into the central ruling system by the Yuan, Ming and Qing government after the collapse of the Tubo Dynasty, cultural integration has penetrated the history of the Tibetan nation. Therefore, the true feeling of cultural identity is shown through "Gesaer", and the multiethnic cultural integration provides the necessary background for the narrative of the epic "Gesaer".

\subsubsection{Tubo Civilization and Han-Tibetan Culture}

According to historical records, when Princess Wencheng entered Tibet, she introduced various Central Plains cultures such as Buddhist scriptures, books, crafts, and plant varieties to Tibet. Later, she accepted the achievements of Central Plains civilization through marriage with relatives. During the Yuan Dynasty, Tibet was officially brought under the administrative jurisdiction of the central government. During the Ming Dynasty, through the ancient tea-horse road, the Han and Tibetan people realized the exchange of silk, tea, Tibet wools, horses and other items, and also realized civilized association and communication. The "Gesaer" described it like this: The goods are shipped to Tibet, is it because we don't produce these things here? No, it is just to connect the hearts of the people of Han and Tibet together."[5] During the Jiaqing and Daoguang periods of the Qing Dynasty, some of the people stationed in Tibet have integrated with the local Tibetan residents. The close friendly exchanges between the two sides have demonstrated that the two sides have made various kinds of history while also jointly creating Chinese culture.

\section{THROUGH THE STUDY OF THE EPIC "GESAER", SCHOLARS CAN REVEAL THE EXTERNAL INFLUENCE MECHANISM AND DEVELOPMENT TREND OF THE CHINESE NATION'S ASSOCIATION, COMMUNICATION, AND INTEGRATION, AND CREATE SOCIAL CONDITIONS FOR THE REALIZATION OF THE CHINESE NATION'S ASSOCIATION, COMMUNICATION, AND INTEGRATION}

The study of the epic "Gesaer" is helpful to understand the symbiotic relationship between the mother culture of the Chinese nation and the subcultures of various nationalities, and to comprehend the common cultural psychological structure of the Chinese nation. From "Gesaer", people can explore the inner context and future trend of Tibetan culture and even Chinese culture to guide the actions today with the understanding of the regularity of the integration and development of Chinese multiethnic culture itself.

The epic "Gesaer" not only circulated in Tibet, but also spread to Mongolian, Tu, Naxi, and Yugu regions. In 1984, the Propaganda Department of the Central Committee of the Communist Party of China issued Document No. 7, approved and forwarded the "Report of the Chinese Academy of Social Sciences on Further Strengthening the Work of 'Gesaer'", and approved the establishment of the "National 'Gesaer' Work Leading Group", aiming to systematically collect and organize "Gesaer" circulating in Tibet, Qinghai, Inner Mongolia, Sichuan, Yunnan, Gansu, Xinjiang and other places. More valuable is the recording of more than 3,000 tapes performed by Gesaer rap artists, and Northwest Minzu University has specially set up the "Gesaer College" department. It can be seen that the study of "Gesaer" has gradually shifted from a purely historical study to a study of ethnic communication and ethnic communication, making the study of Gesaer a holistic, comprehensive and macroscopic study. 


\subsection{Extracting the Epic "Gesar" Praising the Progressive Concept of Unity and Opposing Division, and Studying the Internal Influence Mechanism of the Chinese Nation's Association, Communication, and Integration}

The common cultural psychological structure formed by the various Chinese nationalities in the long history of thousands of years, and the patriotic ideology of maintaining national unity and the unity of the motherland inspired by the central cohesion point of this cultural psychological structure. For example: Many passages of "Gesaer: Jia-Ling Legend" are exaggerating Sino-Tibetan friendship, such as: the milk girl sang for Gesaer's adviser $\mathrm{Mu}$ Wan when her dream came true:

On the Minister Xiang Wan's tent,

There is a piece of Han silk floating up,

Han's white silk appeared in Tibet,

Symbolizing the friendship between Han and Tibet. [6]

Another example is when Gesaer bid farewell to the emperor of the Central Plains when he returned home, the seven sisters of princesses and saw him off, and Lu Mucuo sang:

There are eighteen hada in different colors,

It's a farewell gift for the seven of our sisters,

Dedicating Hada to the lion king with both hands,

May Jia-Ling pass on friendship from generation to generation. [6]

It can be seen from the lyrics that the Tibetan people at that time were already longing for the association and communication between the two ethnic groups, and longing for national unity, reflecting the patriotism of the motherland's reunification.

\subsection{Based on the Epic "Gesaer", People Can Study the Central Plains Culture Represented by the Three Schools of Confucianism, Buddhism and Taoism, Assimilate and Blend the Western Regions, Liao and Jin Cultures, Western Xia culture, Tibetan Culture, and Manchurian and Mongolian Cultures, and Realize the Association, Communication, and Integration of Chinese Nationalties}

In China's history, the Central Plains region was the political, economic and cultural center at that time. Through wars, envoys, marriages, intermarriage, trade, etc., the Central Plains Han culture was continuously exported. On the basis of the integration of the surrounding ethnic groups with the Han culture, the Western Regions, Liao and Jin, Western Xia, Tibetan, and Manchurian and Mongolia cultures were formed. The cultures of all ethnic groups embodies the characteristics of the overall Chinese culture, realizing the association, communication, and integration among the various ethnic groups in China. For example: "In the eighth year of Zhenguan, Songtsen Gampo sent envoys to pay tribute." It is a record of Tibetan and Han envoys in history; "The Tubo Zanpu sent his prime minister Lu Dongzan to offer five thousand taels of gold and hundreds of treasures to invite marriage. Songtsen Gampo promise Princess Wencheng principal wife." It is a historical record of TibetanChinese marriage relations. The same examples also occurred in Han culture and Western culture, Han culture and Liao-Jin culture, Han culture and Western Xia culture, and Han culture and Manchurian and Mongolian culture.

\subsection{Based on the Epic "Gesaer", Scholars Would Be Able To Study the Large- scale Communication and Integration Between the Tibetan People and the Inland Ethnic Goups in Politics, Economy, Culture, and Art, and the Spiritual and Cultural Exchanges Between Tibet and the Inland Ethnic Groups}

The "Gesaer: Jia-Ling Legend" in "Gesaer" describes the story of Gesaer from the ridge to the Central Plains, helping the emperor of the Central Plains to kill demons and eliminate demons. It expresses the Sino-Tibetan friendship. The plot 
portrayed in this chapter is a testament to the history of interaction between the Tibetan nation and the Han nation, and even the Tibetan nation and other nations. It reflects the interactive relationship between the various nations in China and the formation of Chinese culture. The "Gesaer: Jia-Ling Legend" reflects this historical content in a unique form of epic art. Therefore, the epic of "Gesaer" is not only a manifestation of Tibetan culture, but also a part of Chinese culture, reflecting Han-Tibetan culture, branding with cultural fusion and praising the unity and unity of the nation.

\section{CONCLUSION}

To sum up, the internal logic of the research field of ethnic association, communication and integration and the ethnic relationship between national identity and ethnic culture is the research focus, and the internal logic of the social relationship between the research field of national association, communication and integration and social capital and ethnic habituation is also the research focus. The comparison and translation of epic "Gesaer" documents, Tibetan historical materials and historical materials, Tibetan local chronicles, Tibetan ethnography and Tibetan survey materials, are the difficult points in the study.

The formation of Tibetan culture has not only the role of history, geography, culture and other factors, but also the baptism and blessing of Han culture. As a subculture of Chinese culture, the two belong to the same cultural ecological environment. Therefore, the symbiotic relationship between Tibetan and Han cultures gave rise to their subsystems that belong to the Chinese culture today. Tibetan culture is a unique ethnic culture in Chinese culture, and it is a part of Chinese culture that is in line with Han culture and other ethnic minority cultures.

\section{AUTHORS' CONTRIBUTIONS}

Jing An is responsible for the writing of the outline and content of the paper, and Qian Xiang is responsible for the collection of paper materials and the revision of the paper.

\section{REFERENCES}

[1] Xinhuanet, Intangible Cultural Heritage: Gesaer [EB/OL]. www.xinhuanet.com/politics/201508/12/c_128122107.htm. 2021-5-8. (in Chinese)
[2] Tao Xiaohui, Ethical Ideas in Gesaer and Ideal Personality of Gesaer [J]. Journal of Tibet University, 2004 (4). (in Chinese)

[3] People's Daily Online, In-depth Study and Implementation of General Secretary $\mathrm{Xi}$ Jinping's Important Expositions on National Work [EB/OL]. http://nm.people.com.cn/n2/2021/0109/c1966 67-34519561.html. (in Chinese)

[4] Xu Guobao, Gesaer and the Multidimensional Centripetal Structure of Chinese Culture [D]. Doctoral Dissertation of Chinese Academy of Social Sciences, CASS, 2000, 4. (in Chinese)

[5] The Historical Origin of the Ancient Tea Horse Road [EB/OL]. http://www.88828.net/lishigushi/yeshi/14306. html, 2021-5-4. (in Chinese)

[6] Jia-Ling Legend [M]. A Tu, Xu Guoqiong, Xie Shiyi, trans. China Folk Literature and Art Publishing House, Dec. 1984. (in Chinese) 